\title{
ERRATUM
}

Adam G. Rehorn · Jin Jiang · Peter E. Orban - E.V. Bordatchev

\section{State-of-the-art methods and results in tool condition monitoring: a review}

Published online: 24 November 2004

(c) Springer-Verlag London Limited 2004

Int J Adv Manuf Technol (2004)

DOI 10.1007/s00170-003-2038-2

Unfortunately, E.V. Bordatchev was not listed as author in the original.

The online version of the original article can be found at http://dx.doi.org/10.10007/s00170-003-2038-2.

A.G. Rehorn (ष) · J. Jiang

Department of Electrical and Computer Engineering,

The University of Western Ontario,

London, Ontario N6A 5B9, Canada

E-mail: adam.rehorn@nrc.gc.ca

A.G. Rehorn - P.E. Orban - E.V. Bordatchev

Integrated Manufacturing Technologies Institute,

National Research Council of Canada,

800 Collip Circle, London, Ontario, N6G 4X8, Canada 